\begin{abstract}
About authors:
Kulygina Elena Sergeevna, postgraduate student of the Department of pediatric surgery; tel.: +79531374666; e-mail: elenakulygina1990@mail.ru; https://orcid.org/0000-0002-8876-5360

Razin Maxim Petrovich, MD, PhD, Professor, Head of the Department of pediatric surgery; tel.: +79128281527; e-mail: mprazin@yandex.ru; https://orcid.org/0000-0003-3561-3256

Minaev Sergey Viktorovich, MD, PhD, Professor, Head of the Department of pediatric surgery; tel.: +79624507653; e-mail: sminaev@yandex.ru; https://orcid.org/0000-0002-8405-6022

Ignatiev Sergey Viktorovich, PhD, Senior Researcher, Center for Hemostasis Pathology, tel.: +79226688920; e-mail: feb74@yandex.ru; https://orcid.org/0000-0002-8457-2967

Akselrov Mikhail Aleksandrovich, MD, PhD, Professor, Head of the Department of pediatric surgery tel.: +79292694933; ; e-mail: akselrov@mail.ru; https://orcid.org/0000-0001-6814-8894

Agalakova Tatyana Borisovna, PhD, Associate Professor, Head of the Department of foreign languages; tel.: +79123650696; e-mail: tbagalakova@yandex.ru; https://orcid.org/0000-0002-5452-098X
\end{abstract}

(c) Group of authors, 2021

UDC 612.216-112:615.37(470.063)

DOI - https://doi.org/10.14300/mnnc.2021.16034

ISSN - 2073-8137

\title{
CONGENITAL DEFECTS IN THE IMMUNE SYSTEM IN THE STAVROPOL REGION
}

Barycheva L. Yu., Khachirova L. S., Golubeva M. V., Kubanova L. T.

\author{
Stavropol State Medical University, Russian Federation
}

\section{ВРОЖАЕННЫЕ АЕФЕКТЫ ИММУННОЙ СИСТЕМЫ B CTABРОПОАЬСКОM KPAE}

\author{
А. Ю. Барычева, А. С. Хачирова, М. В. Голубева, А. Т. Кубанова \\ Ставропольский госуАарственный меАицинский университет, \\ Российская ФеАерация
}

The study analyzed 88 patients with congenital immunodeficiencies registered in the Stavropol Region (SR) during a 10year period (2009-2019). The results established that the prevalence of primary immunodeficiencies (PID) in the SR was 3.1 per 100,000 population. Children affected by PID predominated $(74.7 \%)$ in the cohort of living patients. Twenty-seven nosological forms of PID were verified in the SR register. The most common was defective humoral component of the immune system $(44.3 \%)$, followed by combined immune disorders with syndromic manifestations ( $15.9 \%)$ and phagocytosis defects (10.2\%). The molecular genetic diagnosis was confirmed in $38.6 \%$ of patients. Hematopoietic cell transplantation was performed in $11.4 \%$ of patients. Intravenous immunoglobulin medications were administered in $20.2 \%$ of patients. Mortality in the PID cohort within the SR register was $6.9 \%$.

Keywords: primary immunodeficiencies, register, epidemiological characteristics, therapy

В исследовании осуществлен анализ врожденных дефектов системы иммунитета, выявленных в регионе Ставропольского края (СК) в течение 10 лет (2009-2019). Установлено, что распространенность первичных иммунодефицитов (ПИД) в СК составляет 3,1 на 100000 населения. В когорте живых пациентов преобладают дети (74,7 \%). Наиболее распространенными являются дефекты антителообразования (44,3\%), синдромальные комбинированные иммунодефициты (15,9%), дефекты фагоцитирующих клеток (10,2%). В 38,6 \% случаев диагноз подтвержден молекулярно-генетическими методами. Иммунореконструкция выполнена у $11,4 \%$ детей. Внутривенные препараты иммуноглобулина вводили 20,2 \% пациентов. Смертность ПИД составила 6,9\%.

Ключевые слова: первичные иммунодефициты, регистр, эпидемиологическая характеристика, терапия

For citation: Barycheva L. Yu., Khachirova L. S., Golubeva M. V., Kubanova L. T. CONGENITAL DEFECTS IN THE IMMUNE SYSTEM IN THE STAVROPOL REGION. Medical News of North Caucasus. 2021;16(2):153-158. DOI - https://doi.org/10.14300/mnnc.2021.16034

Для цитирования: Барычева Л. Ю., Хачирова Л. С., Голубева М. В., Кубанова Л. Т. ВРОЖДЕННЫЕ ДЕФЕКТЫ ИММУННОЙ СИСТЕМЫ В СТАВРОПОЛЬСКОМ КРАЕ. Медицинский вестник Северного Кавказа. 2021;16(2):153-158. DOI - https://doi.org/10.14300/mnnc.2021.16034 
G-CSF - granulocyte colony-stimulating factor

IDS - immunodeficient state

PID - primary immunodeficiency
RF - Russian Federation

SR - Stavropol region
$\mathrm{P}$ rimary immunodeficiencies (PID) are genetically determined life-threatening diseases caused by monogenic immune defects that lead to the development of serious infections as well as lymphoproliferative and autoimmune processes associated with impaired immune regulation [14]. Congenital PID, as a group of diseases, were identified less than $\mathbf{5 0}$ years ago and remain a new direction in clinical medicine. Leading experts in the PID field believe that these diseases often remain unrecognized, meaning that delayed diagnosis and treatment are common worldwide [5].

Due to the low awareness of congenital immunodeficiencies in Russia, the country has unjustifiably high disability and mortality of PID patients [6,7], especially given that timely diagnosis and early therapy can prevent the development of severe and irreversible changes, significantly improve the quality of life and prognosis for patients, and change the belief that PID are hopeless and incurable diseases $[4,8,9]$.

The incidence and prevalence of PID are key epidemiological indicators. These data allow prediction of the frequency of PID occurrence and shaping of the most suitable public health policy for their treatment and prevention at regional, national, and international levels [9]. Ethnic and geographical differences can significantly affect the frequency and structure of PID, and thus regional epidemiological data are of significant interest [10].

Material and Methods. To create a PID register, data for all patients with PID diagnosed during a 10-year period (2009-2019) were collected in 35 administrative districts of the Stavropol Region (SR). Registration of patients with PID was carried out at the Department of Immunology, Stavropol State Medical University. The diagnosis of PID was established in accordance with the diagnostic criteria of the European Society for Immunodeficiencies (ESID) [11]. Investigation of the immune status was carried out in the laboratory diagnostics department at the Regional Clinical Consultative and Diagnostic Center (Stavropol), and included immunophenotyping of lymphocytes using one- and two-parameter IQTest reagents (CD19-PC5, HLA-DR-PC5, CD3-FITC/CD4-PE, CD8-PC5, CD3-FITC/ $\mathrm{CD}(16+56)-\mathrm{PE}$, and CD45-ECD; Beckman Coulter, USA) in a Cytomics FC500 laser flow cytometer (Beckman Coulter), determination of serum immunoglobulins $\lg A$, IgG, and IgM by quantitative immunoturbidimetry in an AU680 biochemical analyzer (Beckman Coulter), and a nitro blue tetrazolium chloride restoration test (NBT test).

Molecular genetic research was carried out at the stage of diagnosis clarification by direct Sanger sequencing of the coding regions of genes or genome-wide nextgeneration sequencing with an «immunology panel» in the molecular biology laboratory of Dmitry Rogachev National Medical Research Center of Pediatric Hematology, Oncology and Immunology.

Most of the patients (65.9\%) entered in the register were examined at federal centers: Dmitry Rogachev National Medical Research Center of Pediatric Hematology, Oncology and Immunology and The Russian Children's Clinical Hospital. Data for the patients with PID in the SR were entered into the electronic register of the Russian Federation during 2018-2020. The mandatory condition for registration was signed informed consent provided by the patient or their legal representative.

When analyzing the data, the prevalences of congenital immune disorders were estimated in accordance with the classification of the International Union of Immunological Societies [3], as well as certain nosological forms of PID, taking the results of the molecular genetic research into account. Investigations of the sex composition of the patients, the age at which the first symptoms appeared, and the time taken to reach the diagnosis were performed. The timing of the delay in diagnosis was calculated as the difference between the date of disease manifestation and the date of diagnosis verification.

The Attestat 10.5.1 software package was used for statistical analysis of the data. Quantitative values were presented as median (interquartile range [25th percentile, 75th percentile]). The data were statistically analyzed using Pearson's chi-square test. The study design was approved by our local ethics committee.

Results and Discussion. Between 2009 and July 2020, 88 patients with congenital immunity errors were registered in the SR. At the time of the analysis (July 2020), 79 (87.4\%) patients were alive, 6 (6.9\%) had died, and $3(3.4 \%)$ were lost to observation so their life status could not be assessed. The minimum prevalence of PID was calculated to be 3.1 per 100,000 population, which was higher than the average figures for the Russian Federation, as well as the indicators in many regions of the Russian Federation [4], but markedly lower than those in European countries $[9,12]$.

The reported prevalence of PID worldwide has varied from 1.5 to 18.8 per 100,000 population and is largely determined by socioeconomic and ethnic characteristics, as well as the methodology of data collection and the accuracy of clinical and laboratory diagnosis of PID [4, 9, 12]. Specifically, the published prevalences of PID were 4.2 per 100,000 population in Switzerland [13], 8.0 per 100,000 population in France [9], 5.9 per 100,000 population in Great Britain [14], and 2.72 per 100,000 population in Germany [15] including 7.5 per 100,000 children. The overall prevalence of PID in Middle East and North Africa (MENA) countries was reported to range from 0.81 to 30.5 per 100,000 population [16]. In our opinion, the prevalence of PID in the SR has been significantly underestimated, similar to the case in many other regions of the Russian Federation. As reasons, incomplete data on patients with PID obtained from administrative districts within the SR, and loss of information and registration documentation upon transition of mature patients with PID from a child group to an adult group should be taken into account. However, it should be considered that the main reason is the lack of awareness of PID among doctors of various specialties in the SR, as well as the low diagnostic capabilities of laboratory services, especially in areas remote from the regional center.

The male-to-female patient ratio in the SR register was $1: 2.03$, consistent with the data in the Russian register (1:1.5) [4] and most worldwide registers [12]. This consistency probably arises from the predominance of an $X$-linked nature for the inheritance of certain nosological forms of PID.

Demography. Children predominated $(59 ; 74.7 \%)$ in the cohort of living patients with PID in the SR registry at the time of the study. Regarding age groups, $1(1.3 \%)$ patient was aged $<1$ year, $11(13.9 \%)$ were aged $1-4$ years, $26(32.9 \%)$ were aged 5-9 years, and 21 (26.6\%) were aged $10-18$ years. The adult group included 20 (25.3\%) patients.

The median age of patients in the SR register was $10(5.4,17)$ years. At the time of the analysis, the youngest 
patient was aged 3 months and the oldest patient was 74 years. Eight patients in the adult group (40\%) were mature patients diagnosed in childhood. The median age in the pediatric cohort was $7(5,11.2)$ years. The median age in the adult cohort was $26(20.7,42.5)$ years.

The data in the present study largely coincide with the data in the Russian Federation register, in which the proportion of adults is $70.3 \%$ [4], and are consistent with the tendency for adults to prevail in the registers of developed countries worldwide. For example, children aged under 16 years comprise only $17 \%$ in the United Kingdom PID registry [14] and $45 \%$ in the German register (PID-NET) [15], while children aged under 18 years comprise $31 \%$ in the Swiss national register [13] and $25 \%$ in the USIDNET register [5]. According to ESID statistics, the share of the pediatric cohort among patients registered in Europe is $44.3 \%$ [11, 12], while children account for $80 \%$ in most MENA country registers [16].
The prevalence of the pediatric population with PID in the $\mathrm{SR}$ register, and the similar prevalences in most regions of the Russian Federation, is probably due to the lack of awareness regarding PID among therapists, the significant share of humoral immunodeficiencies observed in adult PID and their milder course, and the presence of only one center in Russia that treats adult patients with PID [4].

The main PID groups in the SR registerwere represented by 27 nosological forms (Table). The most common PID was defective humoral component of the immune system (44.3\%, 39 patients), followed by combined immune disorders with syndromic manifestations (15.9\%, 14 patients), phagocytosis disorders (10.2\%, 9 patients), autoinflammatory diseases or complement deficiencies ( $8 \%, 7$ patients each), and combined IDS (SCID/CID) and immune regulation disorders $(6.8 \%, 7$ patients and $4.5 \%$, 4 patients, respectively). Unspecified PID accounted for $2.3 \%$ (2 patients) (Fig. 1).

Table

Distribution of PID in the cohorts of children and adults in the SR register (July 2020)

\begin{tabular}{|c|c|c|c|c|}
\hline \multirow{2}{*}{$\begin{array}{l}\text { IUIS } \\
\text { gro- } \\
\text { up }\end{array}$} & \multirow{2}{*}{ PID category } & \multirow{2}{*}{$\begin{array}{c}\text { Total } \\
\text { amount } \\
(\mathrm{n}=88)\end{array}$} & \multicolumn{2}{|c|}{$\begin{array}{l}\text { Living } \\
\text { patients with known life } \\
\text { status }(n=79)\end{array}$} \\
\hline & & & $\begin{array}{c}<18 \text { years } \\
(n=59)\end{array}$ & $\begin{array}{c}\geq 18 \text { years } \\
(n=20)\end{array}$ \\
\hline I & $\begin{array}{l}\text { Defects of the cellular and humoral components of immune system (SCID / CID) } \\
\text { T-B + SCID } \\
\text { T-B-SCID } \\
\text { Unspecified Combined IDS (CID) }\end{array}$ & $\begin{array}{l}6 \\
3 \\
2 \\
1\end{array}$ & $\begin{array}{l}4 \\
1 \\
2 \\
1\end{array}$ & \\
\hline II & $\begin{array}{l}\text { Combined immunodeficiencies associated with syndromic manifestations } \\
\text { Wiskott-Aldrich syndrome } \\
\text { Louis Bar syndrome (ataxia-telangiectasia) } \\
\text { Nijmegen breakage syndrome } \\
\text { Hyper IgE Syndrome (HIES) } \\
\text { Anhidrotic ectodermal dysplasia with } \\
\text { immune deficiency (EPIDA-ID) } \\
\text { DiGeorge syndrome }\end{array}$ & $\begin{array}{l}14 \\
3 \\
7 \\
1 \\
1 \\
1 \\
1\end{array}$ & $\begin{array}{l}11 \\
3 \\
4 \\
1 \\
1 \\
1 \\
1\end{array}$ & \\
\hline III & $\begin{array}{l}\text { Mostly humoral defects } \\
\text { X-linked agammaglobulinemia (XLA) } \\
\text { Common variable immunodeficiency (CVID) } \\
\text { Hyper- IgM-syndrome, unspecified } \\
\text { Isolated IgG subclass deficiency } \\
\text { Undifferentiated hyperimmunoglobulinemia } \\
\text { Selective IgA deficiency (SDIgA) }\end{array}$ & $\begin{array}{l}39 \\
1 \\
4 \\
3 \\
1 \\
2 \\
28\end{array}$ & $\begin{array}{l}26 \\
1 \\
2 \\
1 \\
22\end{array}$ & $\begin{array}{l}12 \\
4 \\
2 \\
6\end{array}$ \\
\hline IV & $\begin{array}{l}\text { PID with immune dysregulation } \\
\text { 1. Hemophagocytic lymphohistiocytosis with hypopigmentation (FHL): } \\
\text { Griscelli syndrome type } 2 \\
\text { Hermansky-Pudlak syndrome type } 2 \\
\text { 2. Autoimmune diseases with or without lymphoproliferation } \\
\text { APECED (APS-1) } \\
\text { 3. Unspecified autoimmune lymphoproliferative syndrome }\end{array}$ & $\begin{array}{l}4 \\
2 \\
1 \\
1 \\
1 \\
1\end{array}$ & $\begin{array}{l}3 \\
2 \\
1 \\
1 \\
1\end{array}$ & \\
\hline V & $\begin{array}{l}\text { Quantitative and qualitative defects of phagocytes } \\
\text { Congenital neutropenia: } \\
\text { Elastase deficiency (SCN1) } \\
\text { Cyclic neutropenia (Kostmann disease) } \\
\text { Leukocyte adhesion deficiency: } \\
\text { Shwachman-Diamond syndrome } \\
\text { Defective respiratory burst } \\
\text { X-linked chronic granulomatous disease } \\
\text { Autosomal recessive chronic granulomatous disease }\end{array}$ & $\begin{array}{l}9 \\
1 \\
1 \\
1 \\
5 \\
1\end{array}$ & $\begin{array}{l}1 \\
5 \\
1\end{array}$ & \\
\hline VI & Innate immune defects & - & & \\
\hline VII & $\begin{array}{l}\text { Autoinflammatory diseases } \\
\text { Defective inflammasomes: } \\
\text { Familial Mediterranean Fever } \\
\text { CINCA Syndrome (chronic infantile neurological cutaneous and articular syndrome) } \\
\text { (NLRP3 GoF) } \\
\text { Muckle-Wells Syndrome } \\
\text { Marshall Syndrome (PFAPA) }\end{array}$ & $\begin{array}{l}7 \\
3 \\
1 \\
1 \\
2\end{array}$ & $\begin{array}{l}5 \\
3\end{array}$ & 1 \\
\hline VIII & $\begin{array}{l}\text { Complement deficiencies } \\
\text { Defective complement regulation } \\
\text { C1 inhibitor deficiency }\end{array}$ & $\begin{array}{l}7 \\
7\end{array}$ & & $\begin{array}{l}7 \\
7\end{array}$ \\
\hline IX & $\begin{array}{l}\text { Phenocopies caused by somatic mutations } \\
\text { Cryopyrinopathy (NLRP3) }\end{array}$ & - & & \\
\hline & Unspecified PID & 2 & 2 & - \\
\hline
\end{tabular}




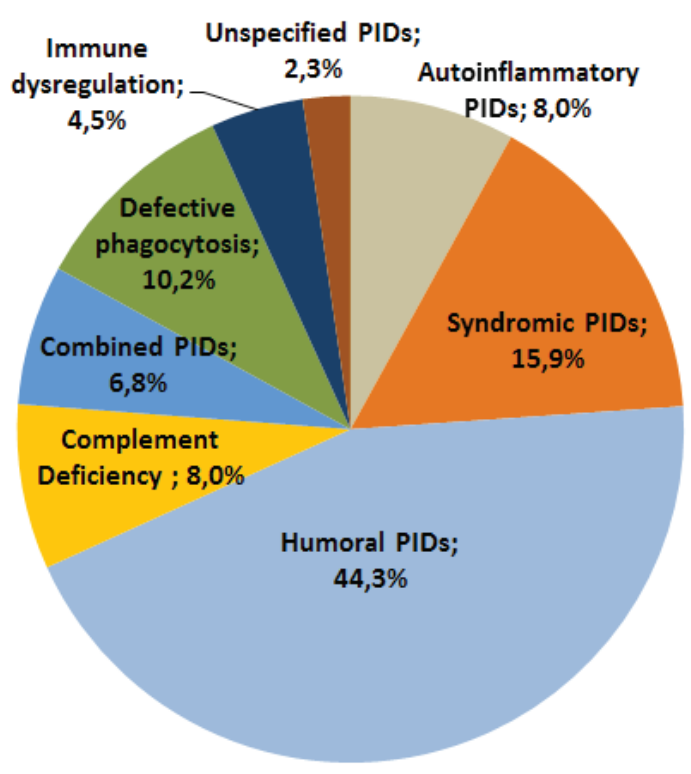

Fig. 1. PID frequency in the SR register

Regarding the forms of PID in the SR register, defects in antibody formation were more common in the SR register compared with the Russian Federation register (44.3\% vs. $28 \%, p<0.001$; Fig. 1, 2). No differences were found compared with the ESID register (Fig. 3). There were no patients in the SR register with defects in innate immunity (group VI) and phenocopies due to somatic mutations (group IX). These groups were recently included in the classification of PID, and consequently their diagnosis is only just beginning to improve. A predominance of humoral and syndromic PID is specified in the majority of world registers [2, 13-15, 17]. The exception is the registers in MENA countries, wherein the proportion of combined IDS is higher and associated with the occurrence of closely related marriages [16].

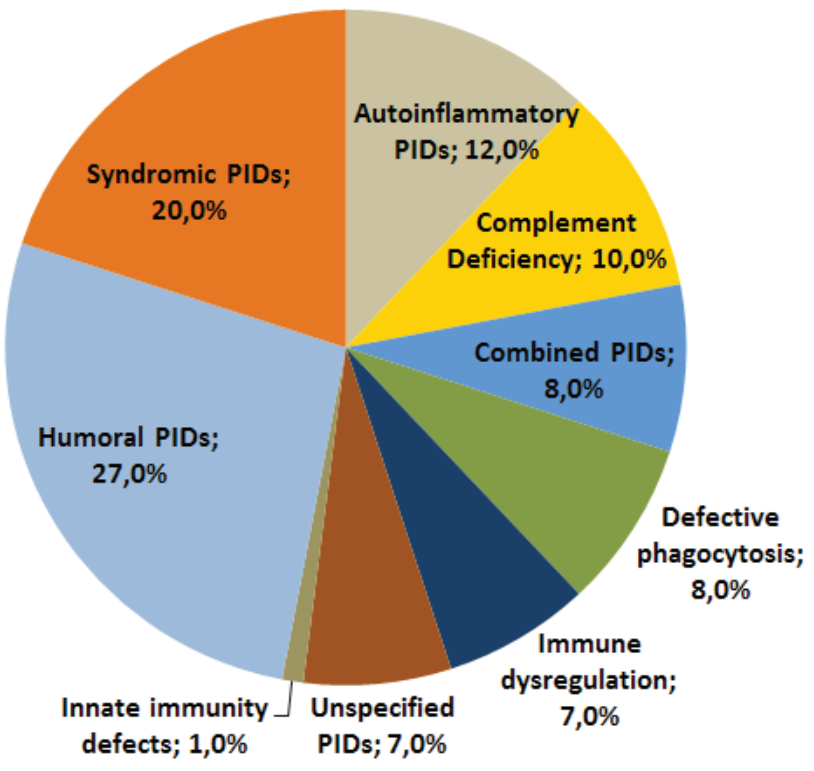

Fig. 2. PID frequency in the RF register [4]

The most frequent nosological form in the SR register was selective IgA deficiency in 28 patients $(31.8 \%)$ (Table). Louis-Bar syndrome (7 patients, $8 \%)$, chronic granulomatous disease (6 patients, $6.8 \%$ ), and hereditary angioedema (7 patients, $8 \%$ ) prevailed among the severe forms of IDS, while common variable immune deficiency (CVID) (4 patients, $4.5 \%$ ) was less common, as were Wiskott-Aldrich syndrome ( 3 patients, $3.4 \%$ ), familial Mediterranean fever (3 patients, $3.4 \%$ ), and hyper IgM syndrome (3 patients, $3.4 \%$ ).

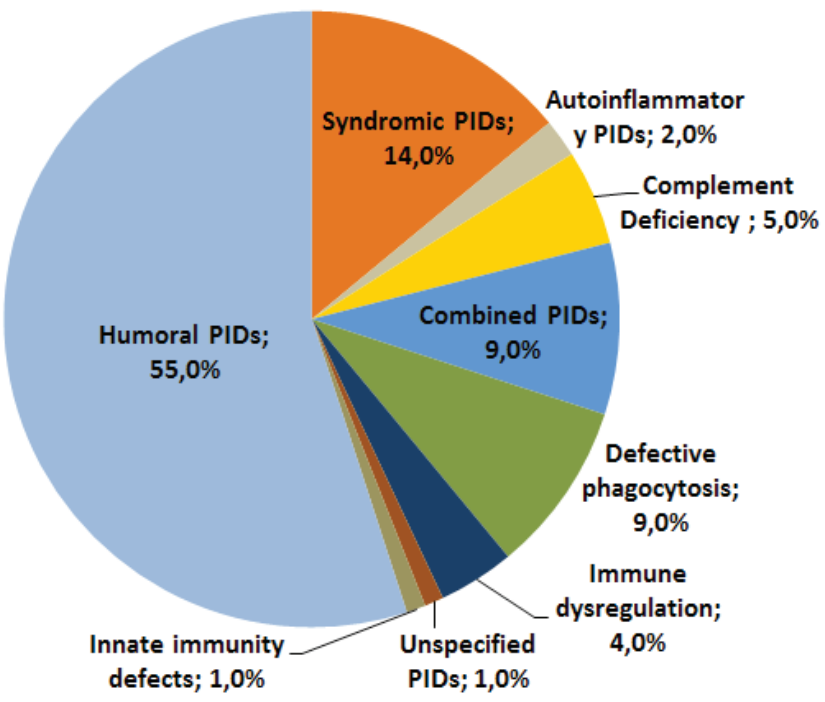

Fig. 3. PID frequency in the ESID register [11]

Two rare cases of hemophagocytic lymphohistiocytosis with hypopigmentation (Griscelli syndrome type 2 and Hermansky-Pudlak syndrome) were diagnosed in the forms of PID with immune dysregulation. T-B +SCID with defective IL2RG (2 patients), JAK 3 deficiency, T-B-SCID with deficiency in adenosine deaminase, and DNA ligase 4 were found among the combined IDS patients. The genetic reason could not be established in one patient with combined IDS.

DiGeorge syndrome (1.1 \%), Nijmegen breakage syndrome $(1.1 \%)$, and X-linked agammaglobulinemia $(1.1 \%)$, often found in most registers worldwide $[5,14,18]$, were represented by isolated cases due to the low awareness of doctors regarding these nosological forms or the absence of obvious infectious episodes in DiGeorge syndrome. Defective humoral component of the immune system and complement deficiencies were verified in 20 adult patients. Among 8 adults diagnosed in childhood, 6 were found with defective humoral component of the immune system, including CVID (2 patients), unspecified hypoimmunoglobulinemia (1 patient), and selective IgA deficiency (3 patients), one patient with hereditary angioedema, and one with Muckle-Wells syndrome. Early infant mortality of boys could be traced in the family histories of 4 children, including those with Wiskott-Aldrich syndrome (1 patient), chronic granulomatous disease ( 2 patients), and Griscelli syndrome 2 (1 patient). A closely related marriage (mother and father were cousins) was found in two families.

Delay in diagnosis. The median age of symptom onset in PID patients in the SR register was $2(0.28,8.5)$ years, including $1.0(0.16,2.64)$ year in the pediatric cohort and $15(20,25)$ years in the adult cohort. Representatives of all groups had a significant delay in diagnosis, ranging from 2 to 10 months in patients with combined immunodeficiencies, from 5 months to 3 years in patients with defective immune regulation, from 2 months to 3 years in patients with autoinflammatory diseases, up to 10 years in patients with defective phagocytosis, and up to 50 years in adult patients with complement deficiencies. The median delay in diagnosing PID in the SR was $2.9(0,51)$ years. Children were diagnosed more quickly 
(median, 2.6 years) than adults (median, 3.5 years), with a significant difference $(p<0.001)$.

Regarding small studies conducted around the world, the median delay in diagnosis of PID in children hospitalized in the Mofid Children's Hospital in Iran was 20 months [19], compared with 19 months in Korea [20] and 2.17 years in Mexico [21]. Given the large delay in diagnosing PID in the SR, it is necessary to carry out activities aimed at reducing this delay. Strategies to achieve this goal already exist in the world. The predominant clinical syndromes in patients with PID in the SR register were infections $(73.9 \%)$ and signs of immune dysregulation (18.1\%) in the form of fever, with three-lineage cytopenia, hepatosplenomegaly, and polyserositis verified less often in the onset of the disease. Recurrent «cold» angioedemas were detected in the clinical picture in $8 \%$ of patients.

The most common infectious complications in patients with PID were pneumonias (43.2\%), including cytomegalovirus infections with SCID (2 patients), staphylococcal infections with formation of pneumocele and bronchopleural fistula with hyper IgE syndrome (1 patient), prolonged destructive infections caused by nocardia with chronic granulomatous disease (2 patients), pneumococcal infections with rapid formation of cylindrical bronchiectasis with CVID (4 patients) and hyper IgM syndrome (1 patient). Frequent infections also included purulent otitis media (20.5\%), sinusitis $(22.7 \%)$, skin infections (21.6\%), purulent lymphadenitis (11.4\%), aphthous stomatitis $(6.8 \%)$, and gastroenteritis (8\%). Hemocolitis developed in $4.5 \%$ of children including those with Wiskott-Aldrich syndrome (2.3\%), HermanskyPudlak syndrome (1.1\%), and chronic granulomatosis (1.1 \%). Repeated viral respiratory infections were observed in $39.8 \%$ of children and prevailed in patients with selective IgA deficiency.

The most common non-specific clinical syndromes were hepatosplenomegaly $(29.5 \%)$ and unspecified fever $(13.6 \%)$, which were observed before making the diagnosis in almost all patients with autoinflammatory diseases and PID with immune dysregulation. Cytopenia was recorded in 21 (23.9\%) children. In 12 (13.6\%) cases, severe three-lineage cytopenia occurred, including patients with SCID (2 patients), syndromic IDS (3 patients), defective immune regulation (3 patients), and phagocytosis disorders (4 patients). Malignant neoplasms accounted for $4.5 \%$ and were observed with ataxia-telangiectasia (2 patients), Nijmegen syndrome (1 patient), and hyper IgM syndrome (3 patients).

Ranking of clinical syndromes by predominance of infections is noted in the German register (2019) [15] and the South African register (ASID) [22], as well as in the registers of other countries and regions [15, 19, 20, $22,23]$. However, due to the differences in classifications among different years, direct comparisons of prevalence rates are difficult to implement [15].

A genetic investigation was performed in 40 $(45.5 \%)$ patients, and the molecular genetic diagnosis was established in $38.6 \%$ of cases, amounting to $85 \%$ of the number tested. According to the Russian Federation register, $36 \%$ of children with PID have genetic confirmation of their diagnosis [4]. The registers in European and Middle East countries have similar indicators accounting for $43.3 \%$ of patients in France [10], 36.4 \% in Germany [15], 33.1 \% in Iran [23], $36.5 \%$ in the United States [5], and $53 \%$ in Kuwait [24]. As in most other countries, a genetic investigation was not conducted for patients with general variable immunodeficiency and selective IgA deficiency due to the high cost of the analysis and the obviousness of the diagnosis as a result of dynamic assessment of serum immunoglobulins [15].

Hematopoietic cell transplantation (HCT) was performed in $11.4 \%$ of children, and 3 patients currently need to undergo HCT. According to the Russian Federation register, immunoreconstructive therapy was carried in $10.8 \%$ of patients [4], compared with $12.2 \%$ in the German register (PID-NET) [15], $10.8 \%$ in the French register (CEREDIH) [9], $3.5 \%$ in the Swiss register [13], and $16.2 \%$ in the Hong Kong register [25]. Furthermore, $23(29.1 \%)$ of the 79 living patients require replacement therapy with intravenous immunoglobulins, and $16(69.6 \%)$ patients regularly receive treatment. Five adult patients occasionally receive replacement therapy. Two children do not receive treatment due to their parents' refusal. Continuous preventative antimicrobia therapy is conducted in $14(17.7 \%)$ of the 79 living patients. Granulocyte colony-stimulating factor (G-CSF) replacement therapy is administered in $6(7.6 \%)$ patients, targeted anticytokine therapy in 7 (8.9\%) patients, C1 inhibitor medications in $4(5 \%)$ patients, and colchicine in $3(3.8 \%)$ patients.

According to the Russian Federation register, $44.7 \%$ of patients receive intravenous immunoglobulin therapy, $37.7 \%$ of patients receive preventative antimicrobial therapy, $7.6 \%$ of patients receive targeted anticytokine therapy, and $4.9 \%$ of patients receive regular or occasional G-CSF [4].

Six $(6.9 \%)$ patients died in the SR since 2009, comparable to the rates in the registers for the Russian Federation (6\%) [4], Germany (2\%) [15], and Switzerland (3.5\%) [13], but slightly less than the rates in the registers for southern China (15.2\%) [26] and Korea $(9.8 \%)$ [20].

Conclusions. The minimum prevalence of PID in the SR is 3.1 per 100,000 population. Women predominate over men (2.03:1) in the SR register. The median age of the patients is 10 years. The most common PID are defective humoral component of the immune system (44.3\%), followed by combined immune disorders with syndromic manifestations $(15.9 \%)$ and defective phagocytosis (10.2\%). The register contains 27 specified nosological forms of PID. Molecular genetic diagnosis is confirmed for $38.6 \%$ of patients.

Symptoms onset age ranges from 0 to 25 years. The prevailing clinical manifestations are infections (73.9\%), with less common manifestations being signs of immune dysregulation (18.1\%) and recurrent «cold» angioedemas ( $8 \%$ ). The diagnostic delay is 2.9 years. HCT is performed in $11.4 \%$ of patients. Replacement therapy with intravenous immunoglobulin medications is received by $21.5 \%$ of patients, continuous preventative antimicrobial therapy by $17.7 \%$, and targeted anticytokine therapy by $8.9 \%$. Mortality in the PID cohort within the SR register is $6.9 \%$.

Disclosures: The authors declare no conflict of interest.

Acknowledgments. The authors are grateful to Scherbina A. Yu., the Head of the Department of Immunology, Professor, MD, to the employees of the Department of Immunology of Dmitry Rogachev National Medical Research Center of Pediatric Hematology, Oncology and Immunology for help in examining patients and verifying the diagnosis. The authors thank Alison Sherwin, PhD, from Edanz (https://www.edanz.com/ac) for editing a draft of this manuscript. 


\section{References}

1. Picard C., Bobby Gaspar H., Al-Herz W., Bousfiha A. Casanova J. L. [et al.] International Union of Immunological Societies: 2017 Primary Immunodeficiency Diseases Committee Report on Inborn Errors of Immunity. J. Clin. Immunol. 2018; 38(1): 96-128. https://doi.org/10.1007/s10875-017-0464-9

2. Modell V., Orange J. S., Quinn J., Modell F. Global report on primary immunodeficiencies: 2018 update from the Jeffrey Modell Centers Network on disease classification, regional trends, treatment modalities, and physician reported outcomes. 2018;66(3):367-380. https://doi.org/10.1007/s12026-018-8996-5

3. Yu J. E., Orange J. S., Demirdag Y. Y. New primary immunodeficiency diseases: context and future. Pediatriya named after G. N. Speransky. - Pediatria named after G. N. Speransky. 2019;98(3):8-23. https://doi.org/10.24110/0031-403X-2019-98-3-8-23

4. Mukhina A. A., Kuz'menko N. B., Rodina Yu. A., Kondratenko I. V., Bologov A. A. [et al.] Characteristics of patients with primary immunodeficiency states in the Russian Federation: from birth to old age. Pediatria named after G. N. Speransky. 2019;98(3):24-31. https://doi.org/10.24110/0031-403X-2019-98-3-24-31

5. Sullivan K. E., Puck J. M., Notarangelo L. D., Fuleihan R., Caulde T. [et al.] USIDNET: a strategy to build a community of clinical immunologists. J. Clin. Immunol. 2014;34(4):428-435

https://doi.org/10.1007/s10875-014-0028-1

6. Latysheva E. A. 2013. Primary immunodeficiencies - not a rare disease, but a difficult diagnosis. Common variable immunodeficiency (analysis of clinical cases). Russian Journal of Allergy. - Ros. allergol. zhurn. 2013;1:58-61.

7. Shcherbina A. Yu. Primary immunodeficiencies: Realities of the 21st century. Pediatric Hematology/Oncology and Immunopathology. 2016;15(1):8-9. https://doi.org/10.24287/1726-1708-2016-15-1-8-9

8. Pai S. Y., Logan B. R., Griffith L. M., Buckley R. H., Parrott R. E. [et al.] Transplantation outcomes for severe combined immunodeficiency, 2000-2009. N. Engl. J. Med. 2014:371(5):434-446 https://doi.org/10.1056/NEJMoa1401177

9. Mahlaoui N., Jais J.-P., Brosselin P., Mignot C., Mahlaoui N. [et al.] Prevalence of Primary Immunodeficiencies in France is underestimated. Journal of Allergy and Clinical Immunology. 2017;140(6):1731-1733. https://doi.org/10.1016/j.jaci.2017.06.020

10. Mahlaoui N., Picard C., Bach P., Costes L., Courteille V. [et al.] Genetic diagnosis of primary immunodeficiencies: A survey of the French national registry J. Allergy Clin. Immunol. 2019;143(4):1646-1649. https://doi.org/10.1016/j.jaci.2018.12.994

11. Kindle G., Gathmann B., Grimbacher B. The use of databases in primary immunodeficiencies. Curr. Opin. Allergy Clin Immunol. 2014:14:501-508. https://doi.org/10.1097/ACl.0000000000000113

12. Seidel M. G., Kindle G., Gathmann B., Quinti I., Buckland M. [et al.] ESID Registry Working Party and collaborators. The European Society for Immunodeficiencies (ESID) Registry Working Definitions for the Clinical Diagnosis of Inborn Errors of Immunity. J. Allergy Clin. Immunol. Pract. 2019;7(6):1763-1770 https://doi.org/10.1016/j.jaip.2019.02.004

13. Marschall K., Hoernes M., Bitzenhofer-Grüber M., Jandus P., Duppenthaler A. [et al.] The Swiss National Re- gistry for Primary Immunodeficiencies: report on the first 6 years' activity from 2008 to 2014 . Clin. Exp. Immunol. 2015;182(1):45-50. https://doi.org/10.1111/cei.12661

14. Shillitoe B., Bangs C., Guzman D., Gennery A. R., Longhurst H. J. [et al.] The United Kingdom Primary Immune Deficiency (UKPID) registry 2012 to 2017. Clin. Exp. Immunol. 2018; 192(3): 284-291. https://doi.org/10.1111/cei.13125

15. El-Helou S. M., Biegner A. K., Bode S., EhI S. R., Heeg M. [et al.] The German National Registry of Primary Immunodeficiencies (2012-2017). Front. Immunol. 2019;10:12721272. https://doi.org/10.3389/fimmu.2019.01272

16. Al-Mousa H., Al-Saud B. Primary immunodeficiency diseases in highly consanguineous populations from middle East and North Africa: epidemiology, diagnosis, and care. Front. Immunol. 2017:8:678-678. https://doi.org/10.3389/fimmu.2017.00678

17. Costa-Carvalho B., Gonzalez-Serrano M., Espinosa-Padilla S., Segundo G. Latin American challenges with the diagnosis and treatment of primary immunodeficiency diseases. Expert. Rev. Clin. Immunol. 2017;13(5):483-489. https://doi.org/10.1080/1744666X.2017.1255143

18. Grimbacher B. The European Society for Immunodeficiencies (ESID) registry. Clin. Exp. Immunol. 2014;178(1):1820. https://doi.org/10.1111/cei.12496

19. Babaie D., Atashpar S., Chavoshzadeh Z., Armin S., Mesdaghi M. [et al.] Surveillance of Primary Immunodeficiency Desorders in Mofid Children's Hospital: A 10-year Retrospective Experience Arch. Pediart. Infect. Dis. 2017;5(4):e61642. https://doi.org/10.5812/pedinfect.61642

20. Rhim J. W. Kim K. H. Kim D. S., Kim B. S., Kim J. S [et al.]. Prevalence of primary immunodeficiency in Korea. J. Korean Med. Sci. 2012;27(7):788-793. https://doi.org/10.3346/jkms.2012.27.7.788

21. Guaní-Guerra E., Jiménez-Romero A., García-Ramírez U. N., Velázquez-Ávalos J. M., Martínez-Guzmán E. [et al.] Disease burden for patients with primary immunodeficiency diseases identified at reference hospitals in Guanajuato, Mexico. PLoS One. 2017;12(4):e0175867. https://doi.org/10.1371/journal.pone.0175867

22. Esser M. M., Nortje R., Potter P. Meeting the needs of primary immunodeficiency patients in South Africa - some findings from the South African registry: PID article. Curr. Allergy Clin. Immunol. 2016;29:56-61.

23. Abolhassani H., Kiaee F., Tavakol M., Chavoshzadeh Z. Mahdaviani S. A. [et al.] Fourth update on the Iranian National Registry of Primary. Immunodeficiencies: integration of molecular diagnosis. 2018;38(7):816-832. https://doi.org/10.1007/s10875-018-0556-1

24. Al-Herz W. Report from the Kuwait national primary immunodeficiency disorders registry (2004-2015). J. Clin. Immunol. 2016;36(3):235-235. https://doi.org/10.1007/s10875-016-0237-x

25. Lam D. S., Lee T. L., Chan K. W., Ho H. K., Lau Y. L. Primary immunodeficiency in Hong Kong and the use of genetic analysis for diagnosis. Hong Kong Med. J. 2005;11(2):90-96.

26. Wu J., Zhong W., Yin Y., Zhang H. Primary Immunodeficiency in south China: clinical features and a genetic subanalysis of 138 children J. Investig. Allergol. Clin. Immunol. 2019;23(5):302-308. PMID:24260974

\section{About autors:}

Barycheva Liudmila Yurievna, MD, PhD, Professor, Head of the Department of immunology with a course of continuing professional education; tel.: +79187405484; e-mail: for_ludmila@inbox.ru; https://orcid.org/0000-0002-4069-0566 Khachirova Liudmila Sergeievna, assistant at the Department of immunology; tel.: +79624258325; e-mail: Iyudmilakhachirova@mail.ru

Golubeva Marina Viktorovna, MD, PhD, Professor, Head of the Department of pediatric infectious diseases; tel.: +78652264312; e-mail: mmvg@rambler.ru; https://orcid.org/0000-0002-0225-3672

Kubanova Leilia Timurovna, senior laboratory assistant at the Department of immunology with a course of continuing professional education; tel.: +79380356967; e-mail: elienbaum141@gmail.com 